\title{
Perceived and objective measures of the food store environment and the association with weight and diet among low-income women in North Carolina
}

\author{
Alison A Gustafson ${ }^{1, *}+$, Joseph Sharkey ${ }^{2}$, Carmen D Samuel-Hodge ${ }^{1}$, \\ Jesse Jones-Smith ${ }^{3}$, Mary Cordon Folds ${ }^{1}$, Jianwen $\mathrm{Cai}^{4}$ and Alice S Ammerman ${ }^{1}$ \\ 'University of North Carolina Center for Health Promotion and Disease Prevention, and Department of Nutrition, \\ Gillings School of Global Public Health, Chapel Hill, NC, USA: ${ }^{2}$ School of Rural Public Health, Department of \\ Social and Behavioral Health and Program for Research in Nutrition and Health Disparities, Texas A\&M Health \\ Science Center, College Station, TX, USA: ${ }^{3}$ University of North Carolina at Chapel Hill Department of Nutrition, \\ Gillings School of Global Public Health, and the Carolina Population Center, Chapel Hill, NC, USA: ${ }^{4}$ University \\ of North Carolina at Chapel Hill Department of Biostatistics, Gillings School of Global Public Health, Chapel \\ Hill, NC, USA
}

Submitted 28 April 2010: Accepted 4 January 2011: First published online 16 February 2011

\begin{abstract}
Objective: The present study aimed to highlight the similarities and differences between perceived and objective measures of the food store environment among low-income women and the association with diet and weight.

Design: Cross-sectional analysis of food store environment. Store level was characterized by: (i) the availability of healthy foods in stores where participants shop, using food store audits (objective); and (ii) summary scores of self-reported perception of availability of healthy foods in stores (perceived). Neighbourhood level was characterized by: (i) the number and type of food stores within the census tract (objective); and (2) summary scores of self-reported perception of availability of healthy foods (perceived).

Setting: Six counties in North Carolina.

Subjects: One hundred and eighty-six low-income women.

Results: Individuals who lived in census tracts with a convenience store and a supercentre had higher odds of perceiving their neighbourhood high in availability of healthy foods (OR $=6 \cdot 87(95 \%$ CI $2 \cdot 61,18 \cdot 01))$ than individuals with no store. Overall, as the number of healthy foods available in the store decreased, the probability of perceiving that store high in availability of healthy foods increased. Individuals with a supercentre in their census tract weighed more $(2 \cdot 40$ (95\% CI $0 \cdot 66,4 \cdot 15) \mathrm{kg} / \mathrm{m}^{2}$ ) than individuals without one. At the same time, those who lived in a census tract with a supercentre and a convenience store consumed fewer servings of fruits and vegetables $(-1 \cdot 22(95 \% \mathrm{CI}-2 \cdot 40,-0 \cdot 04))$.

Conclusions: The study contributes to a growing body of research aiming to understand how the food store environment is associated with weight and diet.
\end{abstract}

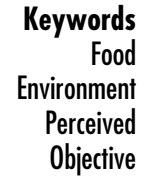

The environment in which a person lives and works can facilitate or impede the accessibility, availability and affordability of healthy food ${ }^{(1)}$. These latter three variables, in turn, may influence individuals' weight and the quality of their $\operatorname{diet}^{(2-7)}$. Widespread recognition of the relationship between the built environment, health status and food choices has led to growing interest in measuring aspects of the food store environment ${ }^{(8-15)}$. However, few studies have examined both subjective $e^{(16,17)}$ and objective

$\dagger$ Correspondence address: RD University of North Carolina Chapel Hill, 250 Seminole Chapel Hill, NC 27514 218-331-2082, USA. measures of the food store environment and their association with weight and diet quality ${ }^{(7,17-22)}$.

Perceived and objective measures each provide unique data that, taken together, can elucidate important factors operating at both the individual and the neighbourhood level. Subjective perceptions about food access and availability, for example, may shape individuals' food purchasing habits ${ }^{(23)}$ and frequency of shopping ${ }^{(24)}$. Objective neighbourhood-level measures, such as in-store food audits or information on store type (collected on-site or from national databases), can supplement perceptual measures, documenting actual food availability in a given locality. 
Simultaneous consideration of both types of measure has the potential to establish a broader context for understanding the environmental determinants of obesity ${ }^{(16)}$.

To date, there is little published research drawing on both objective and perceived measures to explore the relationship between individuals and their food store environment. Moreover, few studies have used both types of measure to examine associations between weight and fruit and vegetable intake ${ }^{(17)}$. Those studies that have assessed the food environment have found only limited associations among diet, weight status and the food environment ${ }^{(4,16)}$. In the USA, studies with an urban and suburban focus have suggested that lack of access to healthy foods in economically and socially disadvantaged neighbourhoods contributes to a lower intake of fruit and vegetables $^{(25,26)}$ and to a higher prevalence of obesity ${ }^{(27)}$. Outside the USA, however, studies have failed to detect any association between food environment and weight or diet quality ${ }^{(28-31)}$.

To address existing gaps in knowledge, the present study was undertaken with both methodological and substantive aims. First, the study sought to highlight similarities and differences between subjective and objective measures of the food store environment at both the individual and the neighbourhood level. Second, the study examined associations between subjective/objective measures of the food store environment and (i) fruit and vegetable intake and (ii) weight status.

\section{Methods}

\section{Study sample}

Individual-level data were obtained from baseline surveys completed by women enrolled in a weight-loss intervention trial (Weight-Wise). Weight-Wise is an evidence-based behavioural weight-loss intervention shown to be effective in low-income women ${ }^{(32)}$. Participants ( $n$ 189) were women aged 40 to 64 years, with incomes at or below $250 \%$ of the federal poverty level, and who had a BMI between 27.5 and $45 \cdot 0 \mathrm{~kg} / \mathrm{m}^{2}$ inclusive. Women were recruited from six county health departments in North Carolina. Four of the six counties are classified as non-metro (less densely populated), while two are classified as metro ${ }^{(33)}$ based on rural-urban continuum codes. Details regarding the study design, intervention components and baseline characteristics have been published elsewhere ${ }^{(32)}$. The University of North Carolina School of Medicine Institutional Review Board approved and monitored the study.

\section{Food store environment}

The study included two objective and two subjective food store environment indicators, measured at both the store and the neighbourhood level. At the store level, the food store environment was characterized by: (i) the availability of healthy foods in stores where Weight-Wise participants shopped, as measured by food store audits (objective); and (ii) summary scores of the women's selfreported perceptions of availability of healthy foods in their primary food store (perceived). At the neighbourhood level, measures of the food store environment included: (i) the number and type of food stores within the census tract (objective); and (ii) summary scores of the women's self-reported perceptions of availability of healthy foods in their neighbourhood (perceived). Each measure is described in greater detail below.

\section{Objective measure of food availability at store level}

Specific food stores where women shopped were identified from a survey question asking 'What is the name and street of the grocery store where you do your primary shopping?' The survey responses regarding the location of the named food store were confirmed using groundtruthing (direct observation of food store addresses) ${ }^{(1,34)}$. To ascertain in-store food availability, we modified items from the Nutrition Environment Measures Survey in Stores (NEMS-S) ${ }^{(35)}$ using data about purchasing habits from the Bureau of Labor Statistics ${ }^{(36)}$ and the US Department of Agriculture Continuing Survey of Food Intakes by Individuals (CSFII). To reflect the purchasing habits of the Weight-Wise study population (low-income southern women), we therefore added frozen and canned goods and pork, while excluding baked goods ${ }^{(37)}$. In the spring and summer of 2009 (after participants had been enrolled into the study), we assessed food availability in all eighty stores identified by participants, focusing on thirty-seven food items in nine food groups: (i) non-fat/low-fat milk; (ii) fruit; (iii) vegetables; (iv) low-fat meats; (v) frozen fruit and vegetables; (vi) canned vegetables; (vii) $100 \%$ wholewheat bread; and (ix) non-sugar-sweetened cereals. All stores were surveyed between 09.00 and 16.00 hours on weekdays to maintain consistency relative to stock on the shelves between stores. A tally sheet was used to determine whether the food item was available at the time of the audit. Each food item received 1 point if available, with a minimum possible survey score of zero and a maximum possible score of 37 . Food store availability then was categorized as low, medium or high (tertiles) to facilitate comparisons with other studies ${ }^{(38)}$.

\section{Objective measure of food availability at neighbourbood level}

We collected several types of data to measure neighbourhood food availability. First, data on the number and type of food stores in all six counties were obtained from InfoUSA, Inc. (Papillion, NE, USA) in August 2008 and 2009 to assure accuracy in addresses over repeated times. Food stores then were classified based on supplemented Standard Industrial Classification (SIC) codes to allow for comparisons with other studies ${ }^{(3,39)}$. Codes included supercentres (e.g. Super Walmart; SIC 531102), convenience 
stores (SIC 541102, 541103), and supermarkets and large and small grocery stores (SIC 541101, 541104-541106). Second, to assess the number of stores in each participant's neighbourhood, home addresses were geocoded and matched to the 2000 US census tracts using Juice analytics software (http://www.juiceanalytics.com) and ArcMap (ArcGIS version 9·2, 1999-2994; ESRI, Redlands, CA, USA). Finally, the objective neighbourhood availability variable was dichotomized as either 'yes' $(\geq 1$ store) for each store type in the census tract or 'no' (none of that store type) ${ }^{(3)}$.

\section{Measure of perceived bealthy food availability and accessibility in neighbourboods and primary food stores}

Participants' self-report of their local food environment was collected via a telephone survey after enrolment into Weight-Wise but before the intervention began. The survey questions were used to measure perceived access to and availability of healthy foods in each woman's neighbourhood (defined as the area approximately 5 miles around her home), as well as availability in her primary food store (described in detail below).

\section{Neighbourhood bealthy food availability}

To assess perceived neighbourhood healthy food availability, participants were asked about the extent to which they agreed with the following statements about their neighbourhood: (i) 'A large selection of fruits and vegetables is available in my neighbourhood'; (ii) 'A large selection of low-fat products is available in my neighbourhood'; and (iii) 'The fruits and vegetables in my neighbourhood are of a high quality'. Responses to all questions were coded on a 5-point Likert scale ( $0=$ 'strongly agree'; $4=$ 'strongly disagree'). The neighbourhood availability questions have previously been tested for reliability and validity and are described elsewhere ${ }^{(4,40)}$.

\section{In-store bealthy food availability}

Participants were also asked about the extent to which they agreed with the following statements for their primary food store: (i) 'A large selection of fruits and vegetables is available'; (ii) 'A large selection of low-fat meat products is available (90\% lean beef, skinless chicken)'; (iii) 'A large selection of brown breads is available'; and (iv) 'A large selection of low-fat cheese or skim milk is available'. Responses to all questions were coded on a 5-point Likert scale ( $0=$ 'strongly agree'; $4=$ 'strongly disagree'). The total possible score on this measure was 0 to 16 , with a higher score indicating higher perceived availability. The food store availability questions were adapted from the neighbourhood questions, after being pre-tested among ten lowincome women in a rural community in North Carolina.

Responses from both neighbourhood questions and food store questions were summed into two separate summary scores (neighbourhood availability and food store availability) and then categorized into high, medium and low availability (tertiles) based on distribution of data.

\section{Accessibility}

Access was defined in two ways: (i) objective potential spatial access (network distance along roads from participant's home to primary food store); and (ii) perceived access (length of time and distance travelled to primary food store). A dichotomous variable was created to group access into easy or difficult access based on bimodal distribution of data. Easy access was defined as living $<5$ miles or $<10$ min travel time to the primary food store $v$. difficult access as $\geq 5$ miles or $\geq 10 \mathrm{~min}$ to the primary food store. The cut-off points of 5 miles or 10 min correspond approximately to the mean response, and are also consistent with the cut-off points used in previous studies ${ }^{(18)}$.

\section{Definition of outcomes}

\section{BMI and weight}

At the beginning of the intervention, participants were weighed to the nearest $0.5 \mathrm{lb}(1 \mathrm{lb}=0.4536 \mathrm{~kg})$ on an electronic scale (Seca 770; Seca Corporation, Columbia, MD, USA). Weight was measured twice and the average of the two measurements was used as the final weight. Height was measured with a portable stadiometer (Schorr Productions, Olney, MD, USA). Both height and weight were measured according to approved protocols ${ }^{(32)}$. BMI was calculated as $\mathrm{kg} / \mathrm{m}^{2}$.

\section{Fruit and vegetable intake}

Fruit and vegetable intake was collected using a validated rapid food survey ${ }^{(41)}$ which assessed fruit, vegetable and fibre intakes. The survey is effective in identifying persons with high fat intake, low fruit/vegetable intake or low fibre intake. The fruit and vegetable servings per day were determined from the food survey.

\section{Statistical analysis}

Of the 189 women originally enrolled in the intervention, three women were missing all exposure variables on perceived access and were excluded from analyses, leaving a total sample of 186 women for analysis. There were no significant differences on key outcome or exposure variables between the total sample and the missing women. All was analyses were conducted using the STATA statistical software package version 11.0 (StataCorp., College Station, TX, USA).

To estimate the associations between perceived and objective neighbourhood availability, logistic regression with robust standard errors, utilizing White-Huber correction to account for county-level clustering, was used. In relevant models where census tract was the exposure variable, no stores in a participant's census track was used as the referent category. Additionally, models were stratified by store type or by combination of store type based 
on a priori hypothesis and direct field observation of community landscape.

Multinomial (polytomous) logistic models were used to analyse the three-level categorical outcome of perceived food store availability for the three-level exposure variable of objective food store availability. In all cases, low perception or low objective food store availability was used as the reference category.

Multivariable linear regression was used to model the association among fruit and vegetable intake, weight, BMI, and perceived or objective measures of the food store environment.

All associations were adjusted in all models for race (black, white, other), education (years of education completed), income (reported range of household income such as \$US 20000-29999) and smoking status (excluded when fruit and vegetable intake was modelled as outcome). All models included a cluster statement on county since women are nested within the six counties, allowing for robust standard errors. The type I error rate was set at 0.05 for main effects. The inclusion of a random intercept for census tract or store was not warranted (intra-class correlation coefficient of $0 \cdot 001)$.

\section{Results}

The study sample consisted of 186 women with complete data on all variables. Descriptive statistics for subjective and objective measures of the food store environment and shopping habits are shown in Table 1.

Table 2 shows the association between living in a neighbourhood with each type of food store and the odds of perceiving the neighbourhood as high in availability of healthy foods. Individuals who lived in census tracts with at least one convenience store and one supercentre had higher odds of perceiving their neighbourhood as high in availability of healthy foods (OR $=6 \cdot 87$ (95\% CI 2.61, 18.01)) than individuals who did not have any stores in their neighbourhood. Interestingly, our study did not find those who lived in areas with a high density of supermarkets perceived their neighbourhood to have many healthy food items.

Table 3 displays the results for prevalence ratios and predicted probabilities between perceived and objective food store availability. As the number of healthy foods available in a store decreased in objective terms, the probability that participants would perceive the store to have a high availability of healthy foods increased.

Strongly agreeing that the neighbourhood and store had many healthy foods, as indicated by perceived food store environment responses (Table 4), was not associated with any of the outcomes.

Objective food store environment results (Table 5) indicate that individuals with a supercentre in their census tract weighed more $\left(2 \cdot 40(95 \%\right.$ CI $0 \cdot 66,4 \cdot 15) \mathrm{kg} / \mathrm{m}^{2}$, $P=0 \cdot 02 ; \quad 14 \cdot 72 \quad(95 \%$ CI $4 \cdot 32, \quad 25 \cdot 11) \quad \mathrm{lb}, \quad P=0 \cdot 02)$
Table 1 Perceived and objective measures of the food store environment, outcome measures, shopping habits and demographics, North Carolina, 2009 ( $n$ 186)

\begin{tabular}{|c|c|c|}
\hline & $\begin{array}{c}\text { Mean } \\
\text { or } \%\end{array}$ & SD \\
\hline \multicolumn{3}{|l|}{ Perceived neighbourhood availability* } \\
\hline \multicolumn{3}{|l|}{ Perceived food store availability ${ }^{*}$} \\
\hline All foods (range $0-16$ ) & $12 \cdot 6$ & $2 \cdot 4$ \\
\hline \multicolumn{3}{|l|}{ Perceived accesst } \\
\hline Distance in miles & $5 \cdot 5$ & $5 \cdot 9$ \\
\hline \multicolumn{3}{|l|}{ Objective neighbourhood availability* } \\
\hline Supercentres & $0 \cdot 2$ & 0.4 \\
\hline Supermarkets & $2 \cdot 3$ & $2 \cdot 3$ \\
\hline Convenience stores & $2 \cdot 3$ & $2 \cdot 0$ \\
\hline \multicolumn{3}{|l|}{ Objective food store availability* } \\
\hline Food store score (range 0-37) & $34 \cdot 3$ & $3 \cdot 6$ \\
\hline \multicolumn{3}{|l|}{ Objective accesst } \\
\hline Distance in miles & $6 \cdot 1$ & $6 \cdot 4$ \\
\hline \multicolumn{3}{|l|}{ Outcome measures } \\
\hline BMI $\left(\mathrm{kg} / \mathrm{m}^{2}\right)$ & $37 \cdot 0$ & $4 \cdot 7$ \\
\hline Weight (lb)‡ & 219 & $30 \cdot 8$ \\
\hline Fruit and vegetable servings (range $0.41-8 \cdot 47$ ) & 4 & $1 \cdot 7$ \\
\hline Fruit and vegetable score (range $1-25$ ) & 13 & $4 \cdot 6$ \\
\hline \multicolumn{3}{|l|}{ Frequency of shopping (\%) } \\
\hline 1 time per week & 22 & \\
\hline 2 to 3 times per month & 23 & \\
\hline 1 time per month & 8 & \\
\hline \multicolumn{3}{|l|}{ Demographics } \\
\hline Age (years) & 51 & $7 \cdot 4$ \\
\hline Smoking (\%) & 15 & \\
\hline Education (years) & 13 & 1.9 \\
\hline Employed full time (\%) & 32 & \\
\hline Income $\leq$ \$US $29000(\%)$ & 69 & \\
\hline
\end{tabular}

*Higher score indicates greater availability at the store and neighbourhood level of healthy foods.

tAccess is reported or calculated miles from home to primary food store. $\ddagger 1 \mathrm{lb}=0.4536 \mathrm{~kg}$.

Table 2 Odds ratio and $95 \%$ confidence interval for perceived availability of healthy foods by type of store in census tracts, North Carolina, 2009 (n 186)

\begin{tabular}{|c|c|c|}
\hline & \multicolumn{2}{|c|}{$\begin{array}{l}\text { Perceived neighbourhood } \\
\text { availability }\end{array}$} \\
\hline & OR & $95 \% \mathrm{Cl}$ \\
\hline \multicolumn{3}{|l|}{ All stores in census tract ${ }^{\star}$} \\
\hline Low density (reference) & 1.00 & \\
\hline Medium density & $1 \cdot 10$ & $0 \cdot 42,2 \cdot 89$ \\
\hline High density & $2 \cdot 09$ & $0 \cdot 69,6 \cdot 29$ \\
\hline \multicolumn{3}{|l|}{ Store type in census tract } \\
\hline No store by type (reference) & $1 \cdot 00$ & \\
\hline Supermarket & $0 \cdot 77$ & $0 \cdot 23,2.59$ \\
\hline Supercentre & $3 \cdot 76$ & $0.96,14.62$ \\
\hline Convenience & $1 \cdot 66$ & $0 \cdot 59,4 \cdot 64$ \\
\hline \multicolumn{3}{|l|}{ Store combination in census tract } \\
\hline No store by type (reference) & $1 \cdot 00$ & \\
\hline Convenience and supercentre & $6 \cdot 87$ & $2 \cdot 61,18 \cdot 01$ \\
\hline Supercentre and supermarket & $3 \cdot 41$ & $0 \cdot 43,27 \cdot 23$ \\
\hline
\end{tabular}

All models adjusted for race, education, income and age.

*Low density, <2 stores in census tract; medium density, 2-7 stores in census tract; high density, $>7$ stores in census tract.

compared with individuals without one. Individuals who lived in a census tract with a supercentre and a convenience store also consumed fewer servings of fruits and vegetables $(-1 \cdot 22(95 \% \mathrm{CI}-2 \cdot 40,-0 \cdot 04), P=0 \cdot 04)$. 
Table 3 Prevalence ratio (PR) with 95\% confidence interval and predicated probability of perceived and objective food store availability of healthy foods, North Carolina, 2009 ( $n$ 186)

\begin{tabular}{|c|c|c|c|}
\hline All stores combined & PR & $95 \% \mathrm{Cl}$ & Predicted probability \\
\hline \multicolumn{4}{|l|}{ Medium perceived food store availability } \\
\hline High objective food store availability & $0 \cdot 11$ & $0.01,0.86$ & 0.54 \\
\hline Medium objective food store availability & 0.40 & $0.05,3.23$ & 0.63 \\
\hline Low objective food store availability (reference) & 1.00 & & 0.65 \\
\hline \multicolumn{4}{|l|}{ High perceived food store availability } \\
\hline High objective food store availability & 0.09 & $0.01,0.67$ & 0.22 \\
\hline Medium objective food store availability & 0.30 & $0.04,2 \cdot 12$ & 0.28 \\
\hline Low objective food store availability (reference) & $1 \cdot 00$ & & 0.32 \\
\hline
\end{tabular}

All models adjusted for age, race, education and income.

Table 4 Perceived local food environment and the association with diet and weight, North Carolina, 2009 ( $n$ 186)

\begin{tabular}{|c|c|c|c|c|c|c|}
\hline & \multicolumn{6}{|c|}{ Outcome } \\
\hline & \multicolumn{2}{|c|}{ BMI $\left(\mathrm{kg} / \mathrm{m}^{2}\right)$} & \multicolumn{2}{|c|}{ Weight $(\mathrm{lb})^{*}$} & \multicolumn{2}{|c|}{ Fruit/vegetable servings } \\
\hline & $\beta$ & $95 \% \mathrm{Cl}$ & $\beta$ & $95 \% \mathrm{Cl}$ & $\beta$ & $95 \% \mathrm{Cl}$ \\
\hline $\begin{array}{l}\text { Food store accesst } \\
\text { Neighbourhood availability of healthy foodsł }\end{array}$ & -0.83 & $-2 \cdot 39,0 \cdot 73$ & $-1 \cdot 52$ & $-11 \cdot 13,8 \cdot 08$ & $0 \cdot 14$ & $-0.34,0.66$ \\
\hline Low availability & Reference & & Reference & & Reference & \\
\hline Medium availability & -0.92 & $-3 \cdot 76,1 \cdot 92$ & $-5 \cdot 64$ & $-27 \cdot 45,16 \cdot 15$ & 0.70 & $-1 \cdot 36,2 \cdot 77$ \\
\hline High availability & $-0 \cdot 28$ & $-3 \cdot 45,2 \cdot 90$ & $-1 \cdot 81$ & $-23 \cdot 79,20 \cdot 18$ & 0.52 & $-1 \cdot 03,2 \cdot 08$ \\
\hline \multicolumn{7}{|l|}{ Food store availability of healthy foods $\S$} \\
\hline Low availability & Reference & & Reference & & Reference & \\
\hline Medium availability & $1 \cdot 04$ & $-0.50,2.59$ & 3.09 & $-4 \cdot 61,10 \cdot 80$ & -0.44 & $-0.93,0.05$ \\
\hline High availability & $1 \cdot 22$ & $-0.22,2.67$ & $5 \cdot 49$ & $-4 \cdot 42,15 \cdot 40$ & 0.25 & $-0.29,0.78$ \\
\hline
\end{tabular}

Each block represents the coefficient for one separate model. All models adjusted for race, age, education, income and smoking status (latter excluded when fruit and vegetable intake was modelled as outcome).

${ }^{*} 1 \mathrm{lb}=0.4536 \mathrm{~kg}$.

tEasy access is defined as $<5$ miles as first inclusion followed by $<10 \mathrm{~min}$ travel time. $R^{2}$ values $0 \cdot 04-0 \cdot 07$

+Neighbourhood availability: low, $\leq 4$; medium, 4-8; high, $>8$; range $0-12 . R^{2}$ values $0 \cdot 04-0 \cdot 07$.

$\S$ Store availability: low, $\leq 10$; medium, 10-14; high, $>14$; range 6-16. $R^{2}$ values $0 \cdot 04-0.09$.

Table 5 Objective food store environment and the association with weight and diet, North Carolina, 2009 ( $n$ 186)

\begin{tabular}{|c|c|c|c|c|c|c|}
\hline & \multicolumn{6}{|c|}{ Outcome } \\
\hline & \multicolumn{2}{|c|}{ BMI $\left(\mathrm{kg} / \mathrm{m}^{2}\right)$} & \multicolumn{2}{|c|}{ Weight $(\mathrm{lb})^{*}$} & \multicolumn{2}{|c|}{ Fruit/vegetable servings } \\
\hline & $\beta$ & $95 \% \mathrm{Cl}$ & $\beta$ & $95 \% \mathrm{Cl}$ & $\beta$ & $95 \% \mathrm{Cl}$ \\
\hline \multicolumn{7}{|l|}{ Store type } \\
\hline No store by type & Reference & & Reference & & Reference & \\
\hline Supercentre & $2.40(P=0.02)$ & $0 \cdot 66,4 \cdot 15$ & $14.72(P=0.02)$ & $4 \cdot 32,25 \cdot 11$ & -0.34 & $-1 \cdot 23,0 \cdot 55$ \\
\hline Supermarket & $1 \cdot 47$ & $-1 \cdot 23,4 \cdot 16$ & $5 \cdot 18$ & $-8 \cdot 14,18 \cdot 49$ & $0 \cdot 12$ & $-0 \cdot 62,0.86$ \\
\hline Convenience store & $0 \cdot 21$ & $-1 \cdot 46,1 \cdot 88$ & $2 \cdot 03$ & $-11 \cdot 39,15 \cdot 46$ & -0.76 & $-1 \cdot 59,0.07$ \\
\hline Supercentre and convenience & $2 \cdot 64$ & $0.02,5 \cdot 25$ & $17 \cdot 86$ & $-1 \cdot 21,36 \cdot 93$ & $-1.22(P=0.04)$ & $-2 \cdot 40,-0.04$ \\
\hline Supercentre and supermarket & $2 \cdot 96$ & $-0 \cdot 76,6 \cdot 69$ & $15 \cdot 07$ & $-7 \cdot 78,37 \cdot 93$ & $-0 \cdot 16$ & $-1 \cdot 75,1 \cdot 42$ \\
\hline Supermarket and convenience & $2 \cdot 22$ & $-0.74,3.69$ & $3 \cdot 27$ & $-6 \cdot 21,12 \cdot 75$ & $-0 \cdot 19$ & $-0.71,0.33$ \\
\hline \multicolumn{7}{|l|}{ Access to food storet } \\
\hline Easy access & Reference & & Reference & & Reference & \\
\hline Difficult access & $-0 \cdot 11$ & $-1.95,1.73$ & $-0 \cdot 12$ & $-13 \cdot 75,13 \cdot 50$ & $0 \cdot 10$ & $-0.39,0.59$ \\
\hline \multicolumn{7}{|c|}{ Food store availability of healthy foods } \\
\hline Low availability & Reference & & Reference & & Reference & \\
\hline Medium availability & 0.65 & $-3 \cdot 03,4 \cdot 34$ & $5 \cdot 71$ & $-17 \cdot 06,28 \cdot 48$ & $0 \cdot 67$ & $-0 \cdot 75,2 \cdot 09$ \\
\hline High availability & $1 \cdot 13$ & $-2 \cdot 34,4 \cdot 47$ & $8 \cdot 89$ & $-4 \cdot 79,22 \cdot 56$ & 0.73 & $-0 \cdot 77,2 \cdot 23$ \\
\hline
\end{tabular}

Interaction terms significant at $P \leq 0.05$. Each block represents the coefficient for one separate model. All models adjusted for race, age, education, income and smoking status (latter excluded when fruit and vegetable intake was modelled as outcome). $R^{2}$ values $0 \cdot 04-0 \cdot 18$.

${ }^{*} 1 \mathrm{lb}=0.4536 \mathrm{~kg}$.

tEasy access is defined as $<5$ miles or $<10$ min travel time, difficult access as $\geq 5$ miles or $\geq 10$ min travel time.

¥Food availability: low, $<30$ points; medium, 30-35 points; high, $>35$; range 9-37 points.

\section{Discussion}

The present study highlights how subjective and objective measures can provide insight into cross-sectional associations between food store environment, weight, and fruit and vegetable intake. Our study presents conflicting results when comparing subjective and objective measures at the store and neighbourhood levels, while 
pointing to an association between objective (but not subjective) food store environment measures with weight and fruit and vegetable intake.

Our first set of results examined the odds of perceiving a neighbourhood as having healthy food items depending on what stores were available. Our study did not find an association for those who live in areas with a high density of supermarkets perceiving their neighbourhood to have many healthy items. This is not consistent with other studies and a bit surprising ${ }^{(39,42)}$. However, this result may reflect variation in the quality of healthy food items available for purchase in rural supermarkets relative to urban supermarkets, where most of the studies have taken place. For example, although a neighbourhood may have many supermarkets, the actual quality of the food available for purchase may be low and thus individuals in those neighbourhoods perceive the healthy food items to be of low quality. We then found that individuals who live in neighbourhoods with supercentres and convenience stores are more likely to perceive their neighbourhood as high in availability of healthy food items compared with those living in a neighbourhood with no stores. This finding suggests that having multiple food store options, relative to no stores within the census tract, influences perceptions at the neighbourhood level ${ }^{(43)}$.

The second set of results compared perceived and objective measures within the stores where individuals shop. Surprisingly, women who shopped at a grocery store with many healthy foods actually had a lower probability of perceiving their food store as high in availability. One possible explanation for this discrepancy between perceived and actual availability at the store level is that perceived quality, not assessed in our study, may contribute significantly to perceived availability ${ }^{(41)}$. Without an assessment of quality, our objective measure of availability may not have fully captured the foods most likely to be perceived as acceptable for purchase.

Our next set of results used both types of measure to examine the association of food store environment with fruit and vegetable intake and weight. Although we found no associations of the two outcomes with perceptions of the store or neighbourhood, objective measures of the food store environment were associated with weight and diet. Individuals residing in neighbourhoods with supercentres had a higher BMI and lower consumption of fruits and vegetables. Although supercentres in and of themselves may not be directly responsible for increased weight, our findings suggest that supercentres are likely to be markers of neighbourhoods that have other characteristics associated with an 'obesogenic' environment. For example, rural landscapes or 'food swamps' may be more conducive to the building of superstores ${ }^{(44)}$, and may also have a higher density of fast-food restaurants and fewer areas for recreation and physical activity ${ }^{(44-46)}$.

Our study has several limitations. First, objective food store addresses were collected from secondary data sources, which may misrepresent the true number of food stores currently available to residents ${ }^{(1,34)}$. Second, the use of census tracts to define neighbourhoods may not reflect individuals' true neighbourhood habits and exposure level. Third, our study captured only three types of food store, whereas the food store environment may comprise many other non-traditional food outlets (e.g. Dollar Stores $)^{(1)}$. Fourth, because our study sample consisted only of low-income overweight women, our ability to generalize to other populations is limited. Finally, perception-based measures may be subject to measurement error and may be influenced by differing cultural, economic and neighbourhood contexts ${ }^{(16)}$.

\section{Conclusions}

The present study contributes to a growing body of research seeking to understand whether and how the food store environment is associated with weight and diet, especially among low-income and rural residents ${ }^{(1,9,10)}$. Our results, which point to discrepancies between perceived and objective measures of the food store environment, confirm the importance of obtaining both types of measure to deepen our awareness of the food environment and its influence on obesity risk. Additional research is needed to disentangle the respective influence of individual- and neighbourhood-level food environment factors on diet and weight status.

\section{Acknowledgements}

Financial support was provided by the Centers for Disease Control and Prevention (CDC) Dissertation Grant (R36 DP002021-01). The authors have no conflict of interest to report. The authors each contributed to reviewing and development of manuscript. The authors would like to acknowledge the Weight-Wise research team, participants and health department staff.

\section{References}

1. Sharkey JR (2009) Measuring potential access to food stores and food-service places in rural areas in the US. Am J Prev Med 36, 4 Suppl., S151-S155.

2. Black JL \& Macinko J (2008) Neighborhoods and obesity. Nutr Rev 66, 2-20.

3. Morland K, Wing S \& Diez Roux A (2002) The contextual effect of the local food environment on residents' diets: the Atherosclerosis Risk in Communities Study. Am J Public Health 92, 1761-1767.

4. Moore LV, Diez Roux AV, Nettleton JA et al. (2008) Associations of the local food environment with diet quality - a comparison of assessments based on surveys and geographic information systems: the Multi-Ethnic Study of Atherosclerosis. Am J Epidemiol 167, 917-924.

5. Zenk SN, Schulz AJ, Israel BA et al. (2005) Neighborhood racial composition, neighborhood poverty, and the spatial accessibility of supermarkets in metropolitan Detroit. $\mathrm{Am} \mathrm{J}$ Public Health 95, 660-667. 
6. Cheadle A, Psaty BM, Curry S et al. (1993) Can measures of the grocery store environment be used to track communitylevel dietary changes? Prev Med 22, 361-372.

7. Laraia BA, Siega-Riz AM, Kaufman JS et al. (2004) Proximity of supermarkets is positively associated with diet quality index for pregnancy. Prev Med 39, 869-875.

8. Morland K \& Filomena S (2007) Disparities in the availability of fruits and vegetables between racially segregated urban neighbourhoods. Public Health Nutr 10, 1481-1489.

9. Lytle LA (2009) Measuring the food environment: state of the science. Am J Prev Med 36, 4 Suppl., S134-S144.

10. Saelens BE \& Glanz K (2009) Work group I: Measures of the food and physical activity environment: instruments. $\mathrm{Am} \mathrm{J}$ Prev Med 36, 4 Suppl., S166-S170.

11. Story M, Kaphingst KM, Robinson-O'Brien R et al. (2008) Creating healthy food and eating environments: policy and environmental approaches. Annu Rev Public Health 29, 253-272.

12. Brug J, Kremers SP, Lenthe F et al. (2008) Environmental determinants of healthy eating: in need of theory and evidence. Proc Nutr Soc 67, 307-316.

13. Ball K, Jeffery RW, Crawford DA et al. (2008) Mismatch between perceived and objective measures of physical activity environments. Prev Med 47, 294-298.

14. Cummins S (2007) Neighbourhood food environment and diet: time for improved conceptual models? Prev Med $\mathbf{4 4}$ 196-197.

15. Kamphuis CB, Giskes K, de Bruijn GJ et al. (2006) Environmental determinants of fruit and vegetable consumption among adults: a systematic review. BrJ Nutr 96, 620-635.

16. Moore LV, Diez Roux AV \& Brines S (2008) Comparing perception-based and geographic information system (GIS)-based characterizations of the local food environment. J Urban Health 85, 206-216.

17. Sharkey JR, Johnson CM \& Dean WR (2010) Food access and perceptions of the community and household food environment as correlates of fruit and vegetable intake among rural seniors. BMC Geriatr 10, 32.

18. Rose D \& Richards R (2004) Food store access and household fruit and vegetable use among participants in the US Food Stamp Program. Public Health Nutr 7, 1081-1088.

19. Bodor JN, Rose D, Farley TA et al. (2008) Neighbourhood fruit and vegetable availability and consumption: the role of small food stores in an urban environment. Public Health Nutr 11, 413-420.

20. Wang MC, Cubbin C, Ahn D et al. (2008) Changes in neighbourhood food store environment, food behaviour and body mass index, 1981-1990. Public Health Nutr 11, 963-970.

21. Liese AD, Weis KE, Pluto D et al. (2007) Food store types, availability, and cost of foods in a rural environment. $J \mathrm{Am}$ Diet Assoc 107, 1916-1923.

22. Casey AA, Elliott M, Glanz K et al. (2008) Impact of the food environment and physical activity environment on behaviors and weight status in rural US communities. Prev Med 47, 600-604.

23. Kaufman L \& Karpati A (2007) Understanding the sociocultural roots of childhood obesity: food practices among Latino families of Bushwick, Brooklyn. Soc Sci Med 64 , $2177-2188$.

24. Coveney J \& O'Dwyer LA (2009) Effects of mobility and location on food access. Health Place 15, 45-55.

25. Morland K, Wing S, Diez Roux A et al. (2002) Neighborhood characteristics associated with the location of food stores and food service places. Am J Prev Med 22, 23-29.

26. Diez-Roux AV, Nieto FJ, Caulfield L et al. (1999) Neighbourhood differences in diet: the Atherosclerosis Risk in Communities (ARIC) Study. J Epidemiol Community Health 53, 55-63.
27. Morland K, Diez Roux AV \& Wing S (2006) Supermarkets, other food stores, and obesity: the Atherosclerosis Risk in Communities Study. Am J Prev Med 30, 333-339.

28. White M (2007) Food access and obesity. Obes Rev 8, Suppl. 1, 99-107.

29. Pearce J, Hiscock R, Blakely T et al. (2008) The contextual effects of neighbourhood access to supermarkets and convenience stores on individual fruit and vegetable consumption. J Epidemiol Community Health 62, 198-201.

30. Cummins S \& Macintyre S (2006) Food environments and obesity - neighbourhood or nation? Int J Epidemiol 35, 100-104.

31. Giskes K, van Lenthe FJ, Kamphuis CB et al. (2009) Household and food shopping environments: do they play a role in socioeconomic inequalities in fruit and vegetable consumption? A multilevel study among Dutch adults. J Epidemiol Community Health 63, 113-120.

32. Samuel-Hodge CD, Johnston LF, Gizlice Z et al. (2009) Randomized trial of a behavioral weight loss intervention for low-income women: the Weight Wise Program. Obesity (Silver Spring) 17, 1891-1899.

33. US Department of Agriculture, Economic Research Service (2004) Briefing Rooms. Measuring Rurality: Rural-Urban Continuum Codes. http://www.ers.usda.gov/Briefing/Rurality/ RuralUrbCon/Index.htm\#anchor (accessed October 2009).

34. Sharkey JR \& Horel S (2008) Neighborhood socioeconomic deprivation and minority composition are associated with better potential spatial access to the ground-truthed food environment in a large rural area. J Nutr 138, 620-627.

35. Glanz K, Sallis JF, Saelens BE et al. (2007) Nutrition Environment Measures Survey in stores (NEMS-S): development and evaluation. Am J Prev Med 32, 282-289.

36. Bureau of Labor and Statistics (2008) CPI Detailed Report 2008. http://www.bls.gov/cpi/cpid0807.pdf (accessed September 2009).

37. US Department of Agriculture, Agricultural Research Service (2006) Data Tables: Food Intake by Age, Income, Gender, Region, Race 2006. http://www.ars.usda.gov/ SP2UserFiles/Place/12355000/pdf/0708/Table_1_NIN_GEN_ 07.pdf (accessed June 2009).

38. Franco M, Diez-Roux AV, Nettleton JA et al. (2009) Availability of healthy foods and dietary patterns: the MultiEthnic Study of Atherosclerosis. Am J Clin Nutr 89, 897-904.

39. Moore LV \& Diez Roux AV (2006) Associations of neighborhood characteristics with the location and type of food stores. Am J Public Health 96, 325-331.

40. Mujahid MS, Diez Roux AV, Morenoff JD et al. (2007) Assessing the measurement properties of neighborhood scales: from psychometrics to ecometrics. Am J Epidemiol 165, 858-867.

41. Block G, Gillespie C, Rosenbaum EH et al. (2000) A rapid food screener to assess fat and fruit and vegetable intake. Am J Prev Med 18, 284-288.

42. Zenk SN, Schulz AJ, Hollis-Neely T et al. (2005) Fruit and vegetable intake in African Americans income and store characteristics. Am J Prev Med 29, 1-9.

43. Zick CD, Smith KR, Fan JX et al. (2009) Running to the store? The relationship between neighborhood environments and the risk of obesity. Soc Sci Med 69, 1493-1500.

44. Ver Ploeg M (2010) Access to affordable, nutritious food is limited in 'food deserts'. Amber Waves 8, issue 1, 20-27; available at http://www.ers.usda.gov/AmberWaves/March10/ PDF/FoodDeserts.pdf

45. Sturm R \& Cohen DA (2009) Zoning for health? The yearold ban on new fast-food restaurants in South LA. Health Aff (Millwood) 28, 1088-1097.

46. Rose D, Hutchinson PL, Bodor JN et al. (2009) Neighborhood food environments and body mass index: the importance of in-store contents. Am J Prev Med 37, 214-219. 